\title{
Ethylene glycol injection for hydrate formation prevention in deepwater gas pipelines
}

\author{
Sanggono Adisasmito ${ }^{1, *}$ and Enos Parubak $^{1}$ \\ ${ }^{1}$ Department of Chemical Engineering, Institut Teknologi Bandung, Jalan Ganesa No. 10, Bandung 40132, Indonesia
}

\begin{abstract}
The presence of hydrates in deepwater oil-gas-field operations is a fairly frequent issue. It is very important to have a hydrate management strategy for normal operation and while shutdown. The objectives of the work were to mitigate the hydrate formation in the deepwater operation conditions. This study analyzed the sensitivity of the hydrate compound formation process in flow line system with diameter 9.5" with a length of about $22 \mathrm{Km}$ in deep water gas- field, based on actual condition and production rate assumption. Based on the simulation results for the actual production flow rate, hydrate is formed at a distance of about $17991 \mathrm{ft}$ from the wellhead that is in the first segment of the well head to the Pipeline End Manifold (PLEM). For a higher production flow rate, hydrate formation occurs at a distance approaching the wellhead which is part of the first segment. This is because the temperature at the bottom of the deepwater is as low as $40^{\circ} \mathrm{F}$. The addition of MEG to prevent the formation of hydrate compounds was further investigated. Fluid flow modeling was performed under steady state with $\mathrm{CH} 4$ levels of about $87 \%$, pressure of 1900 psia, $125^{\circ} \mathrm{F}$ temperature and 85 MMSCFD production flow rate as the basic conditions. The data used in this research is taken from one of the deepsea gas field in Makassar Strait. Adding MEG dose of $0.175 \%$ mole, lowering the hydrate-forming temperature from $67.8^{\circ} \mathrm{F}$ to $3.2{ }^{\circ} \mathrm{F}$. Similarly, for increasing MEG doses, the greater the decrease in hydrate formation temperature. The addition of MEG dose of $0.175 \%$ mole at each production flow rate gives different working fluid temperature with hydrate formation temperature of $5.5^{\circ} \mathrm{F}$ to $18^{\circ} \mathrm{F}$, so it is safe from the risk of hydrate formation.
\end{abstract}

\section{Introduction}

Deep-sea exploration began in the late 70 s around of the Gulf of Mexico (USA), Brazil and West Africa. In addition to the outskirts of the Straits of Makassar, other Australasian regions are off the coast of East Malaysia and south-west Australia. The development of deep-sea mining is due to two main factors. First, the world's hydrocarbon reserves are dwindling in conventional areas (land and sea-shallow) while demand is always rising. Second, the technology continues to grow and become more controlled. Operation in the deep sea produces ambient sea water conditions that are brought hydrate formation temperature for both oil and gas drilling operations. The system pressure required to flow in the deep-sea waters and up to the riser may result in a shut-in pressure above the hydrate-forming pressure. Thus, the hydrate management strategy for normal operation and when shutdown is required.

The objectives of the work were to mitigate the hydrate formation in the deepwater operation conditions. Usually in the deepwater gas operations, hydrate inhibitor is continuously injected during normal operation, by using methanol or glycol in order to manage the risk of hydrate formation. This allows the operator to shut-in and stay protected from hydrate. The main reason for continuous use of hydrate inhibitors is that the gas often does not have enough heat capacity to operate above the hydrate-forming area during normal operation.

There are a number of exceptions to this approach when it meets the high reservoir temperature criteria (> $100^{\circ} \mathrm{C}$ ) to allow steady state operations above the hydrate-forming zone, high water rates may inhibit the use of chemical inhibitors from an economic point of view and high condensate yields (> $10 \mathrm{bbl} / \mathrm{MMSCF}$ ) that may contain sufficiently high paraffins. Pipeline operations that produce waxy condensate may cause a risk of blockage of the pipe due to deposits of paraffin. In this case, there is a tendency in the deepwater field to consider design alternatives that include passive insulation or hybrid concepts that take advantage of many strategies.

The general practice of experts in the field of oil and gas production is the approach to hydrate control which is divided into 2 ways ie preventive means which avoids precipitation of hydrate thus preventing further downtime by corrective method involving periodic removal of hydrates. Corrective methods increase downtime and production costs. Production in the deep sea requires knowledge of hydrate deposits and the solution may not only require special technical but a combination of a variety of techniques that lead to better results. (Gomes et al., 1996). The risk of hydration can be reduced by removing water from the system and keeping the

* Corresponding author: sanggono@che.itb.ac.id 
operating temperature above the hydrate temperature (using insulation, hot oil, hot water circulation and electric heating) and setting the operating pressure below the hydrate threshold. Methods of preventing hydration include pressure control, use of mechanical methods, thermal insulation, heat treatment, hydrate-forming, and chemical methods.

Pressure control, design and operation of the system with a low enough pressure to keep the fluid out of the hydrate curve. This approach is often impractical for normal operation because the pressure required to transport the production fluid usually exceeds the pressure of hydrate formed at ambient temperature. The mechanical method (pigging), is the process of inserting a scraper rod (called a "pig") into a pipe network. The modern pig has many functions but the main one is to clean the pipe from any solid (hydrate, wax, dirt, etc.)

Thermal insulation, one effective method of hydration prevention is reservoir heat retention. The wellheads usually have temperatures from $175^{\circ} \mathrm{F}$ to $212^{\circ} \mathrm{F}$. If the fluid in the reservoir flows through an underwater pipeline network with a temperature outside $40^{\circ} \mathrm{F}$, the temperature may rapidly cool down towards the hydrate zone occurring determined by the heat transfer coefficient (U) between the pipe and the sea. Thermal insulation works by keeping the fluid flowing above the temperature of the hydrate formed along the production line. Typically it involves filling the annulus entirely or partially with a material that has a low conductivity to prevent heat loss.

Heat treatment involves the use of hot oil, heated vats, steam heat or electric heaters with steel pipes, this is a short-term solution as the temperature cools down in several stages of the system. And also crude oil will lose its mild contents and this can lead to further hydrate formation. This is an expensive method because of the fuel cost required to heat the vessel and the need for high electrical power for electric heaters with steel pipes. Eliminate hydrate formers by removing hydrate-forming molecules by gas-liquid separation. This approach has been proposed for underwater operations where gases and liquids are separated underwater and transported to processing facilities on separate pipelines. Gas pipelines still require hydrate inhibitors through chemical inhibitors but for liquid fluids containing oil and water capable of operating well without hydrate due to the absence of hydrate-forming compounds.

Chemical methods involve the use of inhibitors. Chemical inhibitors can be broadly classified into Low Dose Hydrate Inhibitors (LDHI) and thermodynamic hydrate inhibitors. The goal of a thermodynamic inhibitor is to press the freezing point by shifting the equilibrium to a low temperature thereby reducing the area in which hydrates can be formed. The two-phase modeling approach involves simultaneous solutions of conservation of the mass, momentum and energy equations of each phase (gas and liquid) and using empirical correlations and simple relationships to flow parameters such as interfacial friction, liquid fractions entering in free gas phase and liquid holdup in slug body. Bendiksen et al. (1991) presented a two-phase transient flow (gas and liquid). The flow model considers three mass conservation equations for gas, liquid bulk, and liquid droplets scattered in the gas phase, coupled with interfacial mass transfer, a combination of momentum between the gas with liquid droplets and the momentum equation for liquid film and the energy mix equation of all phases as homogeneous fluids.

\section{Methodology}

Modeling to study hydrate formation is done by building the modeling of underwater pipeline system that is described from well head to surface pipe by using Aspen HYSYS process simulator. In constructing the modeling, data are used in accordance with the fluid conditions present in the field, including pressure, operating temperature, bathymetry, pipe diameter, pipe roughness, pipe conductivity, and heat transfer coefficient of pipe material used.

The modeling of the piping system is divided into several segments to provide pipe elevation conditions in accordance with the presence of pipelines under the sea. Basically a 9.5 "flowline is divided into 3 piping schemes ranging from well to Pipeline End Manifold (PLEM), from PLEM to riser and riser pipes. The exit pressure from the well is $3,500 \mathrm{psig}$ with a temperature of $150^{\circ} \mathrm{F}$ and a flow rate of 85 MMSCFD. After the fluid passes through the PCV (subsea choke valve), there is a decrease in pressure to $1900 \mathrm{psig}$ and temperature $125^{\circ} \mathrm{F}$.

The piping system is divided into schemes as described in the previous modeling baseline. The flowline modeling in the simulator was conducted in segments, based on the bathymetry data. Bathymetry data is obtained from the results of surveys, from the wellhead through PLEM up to the riser, as shown in Table 1.

Table 1. Piping Segment

\begin{tabular}{|c|c|c|}
\hline Sections & Length (ft) & Area \\
\hline Section 1 (1-10) & 6147 & Well - PLEM \\
\hline Section 2 (11-20) & 6570 & Well - PLEM \\
\hline Section 3 (21-30) & 6556 & Well - PLEM \\
\hline Section 4 (31-40) & 6122 & Well - PLEM \\
\hline Section 5 (41-50) & 6673 & PLEM - Riser \\
\hline Section 6 (51-60) & 6699 & PLEM - Riser \\
\hline Section 7 (61-70) & 6615 & PLEM - Riser \\
\hline Section 8 (71-80) & 5985 & PLEM - Riser \\
\hline Section 9 (81-90) & 6619 & PLEM - Riser \\
\hline $\begin{array}{c}\text { Section 10 (91- } \\
100)\end{array}$ & 6683 & PLEM - Riser \\
\hline $\begin{array}{c}\text { Section 11 (101- } \\
\text { riser) }\end{array}$ & 2978 & PLEM - Riser \\
\hline $\begin{array}{c}\text { Section 12 (Riser) } \\
\text { Ser }\end{array}$ & 2159 & Riser \\
\hline
\end{tabular}

With seabed conditions that have many contours, either in the form of a sloping base or a sea trough, it is important to build the appropriate flowline path. This uneven path with indentation will lead to traps and impact the continuity of fluid flow. Taking into account the 
above conditions, the flowline modeling is made in accordance with the conditions or contours in the field.

Pipeline dimensions and flowline conditions used in the modeling are shown in Table 2.

Table 2. Flowline Parameter

\begin{tabular}{|l|c|}
\hline \multicolumn{1}{|c|}{ Parameter } & Values \\
\hline Outer Diameter [in] & 12.94 \\
\hline Inner Diameter [in] & 9.50 \\
\hline Roughness [ft] & 0.003613 \\
\hline Pipe Wall Conductivity [Btu/hr-ft-F] & 26.0005 \\
\hline Ambient Temp [F] & 40.00 \\
\hline Overall HTC (based on O.D) [Btu/hr-ft2-F] & 2.6240 \\
\hline
\end{tabular}

The modeling of the piping system in the Aspen HYSYS simulator is shown in Fig. 1. The drawing shows a series of piping starting from the wellhead for the next to the pipeline and then to the surface facility.

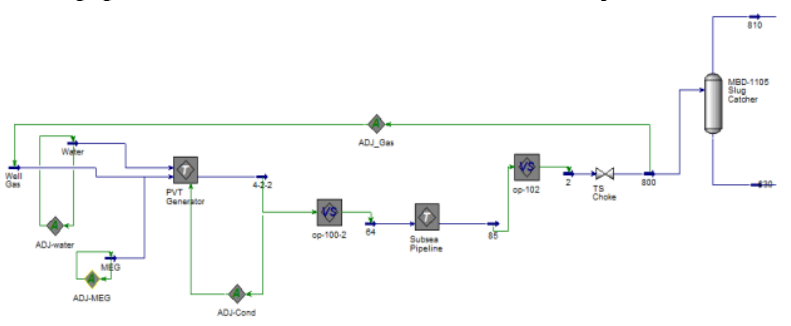

Fig. 1. Piping Chematic in HYSYS

The flowline is divided into 3 segmentations, as shown in Figure 2.

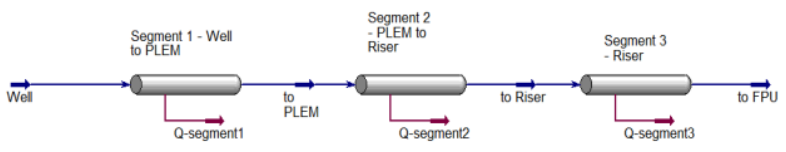

Fig. 2. Piping Segmentation in HYSYS
The operating parameters used as the baseline of the model can be seen in Table 3 .

Table 3. Baseline Operating Parameters

\begin{tabular}{|l|c|}
\hline \multicolumn{1}{|c|}{ Parameter } & Values \\
\hline Temperature [F] & 125 \\
\hline Pressure [psig] & 1900 \\
\hline Molar Flow [MMSCFD] & 85 \\
\hline Mole Fraction $\mathrm{H}_{2} \mathrm{O}$ & 0.0028 \\
\hline
\end{tabular}

The compositions incorporated in Aspen HYSYS v8.8 simulator modeling are the basic compositions obtained from the first exploratory study, as shown in Table 4 . The fluid data entered in the simulation is adjusted in such a way that it can represent the original fluid composition of the state for later inclusion in the Aspen HYSYS simulator.

The temperature profile at each into the sea water can be seen as in Figure 3.

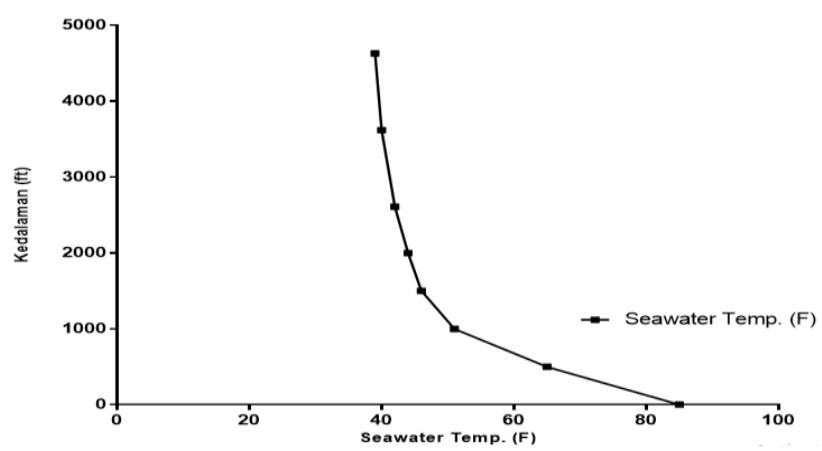

Fig. 3. Temperature profile vs. sea depth.

Table 4. Fluid Composition

\begin{tabular}{|c|c|c|c|c|c|}
\hline Nitrogen & 0,00050 & 28,01 & $-320,44$ & 477,62 & $-232,52$ \\
\hline $\mathrm{CO}_{2}$ & 0,01254 & 44,01 & $-109,39$ & 1054,23 & 87,71 \\
\hline Methane & 0,87240 & 16,04 & $-258,75$ & 658,38 & $-116,41$ \\
\hline Ethane & 0,03973 & 30,07 & $-127,48$ & 693,65 & 90,10 \\
\hline Propane & 0,02758 & 44,10 & $-43,78$ & 602,68 & 206,15 \\
\hline i-Butane & 0,00501 & 58,12 & 10,89 & 514,35 & 274,90 \\
\hline n-Butane & 0,00811 & 58,12 & 31,10 & 535,96 & 305,69 \\
\hline i-Pentane & 0,00290 & 72,15 & 82,18 & 468,80 & 369,05 \\
\hline n-Pentane & 0,00219 & 72,15 & 96,91 & 474,82 & 385,61 \\
\hline n-Hexane & 0,00264 & 86,18 & 155,71 & 425,00 & 454,55 \\
\hline n-Heptane & 0,00452 & 100,21 & 209,17 & 382,24 & 512,61 \\
\hline n-Octane & 0,00597 & 114,23 & 258,21 & 347,41 & 563,81 \\
\hline n-Nonane & 0,00427 & 128,26 & 303,47 & 318,90 & 610,61 \\
\hline n-Decane & 0,00229 & 142,29 & 345,47 & 290,98 & 652,01 \\
\hline n-C11 & 0,00169 & 156,31 & 384,60 & 270,29 & 689,27 \\
\hline $\mathrm{n}-\mathrm{C} 12$ & 0,00126 & 170,34 & 421,30 & 250,71 & 725,27 \\
\hline $\mathrm{n}-\mathrm{C} 13$ & 0,00093 & 184,37 & 455,77 & 235,28 & 756,77 \\
\hline n-C14 & 0,00070 & 198,38 & 488,31 & 220,29 & 789,53 \\
\hline
\end{tabular}




\begin{tabular}{|c|c|c|c|c|c|}
\hline Komponen & Mole Fraction & Mole Weight (lb/lbmole) & $\begin{array}{l}\text { Boiling Point } \\
\text { (F) }\end{array}$ & Critical P (psig) & Critical T $(\mathrm{F})$ \\
\hline $\mathrm{n}-\mathrm{C} 15$ & 0,00051 & 212,41 & 519,11 & 205,30 & 812,93 \\
\hline n-C16 & 0,00038 & 226,43 & 548,22 & 191,34 & 830,93 \\
\hline C17-C19* & 0,00066 & 247,80 & 590,91 & 217,93 & 918,59 \\
\hline C20-C49* & 0,00046 & 316,50 & 709,84 & 169,08 & 1024,57 \\
\hline $\mathrm{H} 2 \mathrm{O}$ & 0,00275 & 18,02 & 212,00 & 3193,54 & 705,47 \\
\hline Total & 1,00000 & & & & \\
\hline
\end{tabular}

\section{Results and discussion}

\subsection{Production flowrate changes}

From the simulation results on the basic operating conditions (without the addition of MEG inhibitor) by making changes to the production flow rate under the same operating parameters conditions, ie fluid composition, temperature, pressure and flowline dimension, the hydrate curve tends to be the same at different flow rates. So it can be concluded that the change in flow rate does not carry a great influence on hydrate formation, as shown in Figure 4 which shows the hydrate forming curve at various production flow rates.

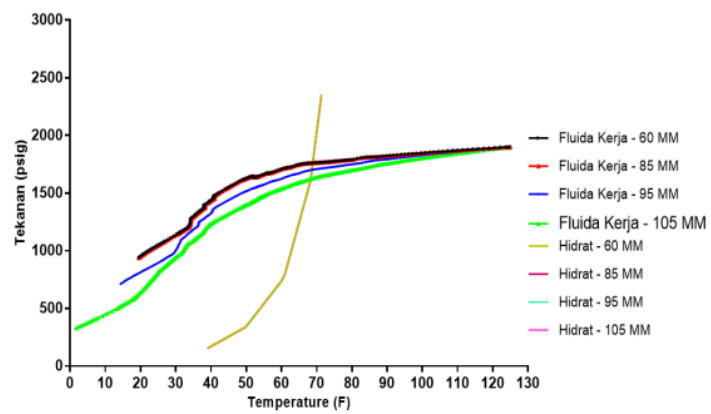

Fig. 4. $P$ \& T fluid profile and hydrate in various flow rate.

Fluid pressure decreases at higher flow rate. This is due to the higher flow rate will experience a greater friction that affects the pressure drop larger. At various flow rates have a tendency similar to the increasingly significant pressure drop in the Riser area to the surface.

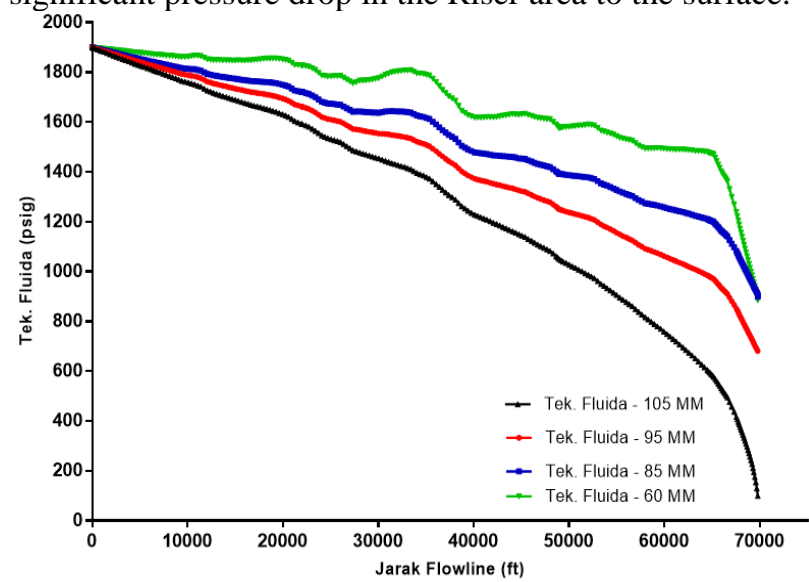

Fig. 5. Fluid pressure profile vs flowline length.
The change in the flow rate does not significantly affect the fluid temperature change but is shown in Figure 6 . Basically the rapidly decreasing temperature occurs at a higher flow rate where the relative temperature change is different from the well head position to a distance of about $27,000 \mathrm{ft}$ and further has a downward trend the same for different flow rates. Significant temperature changes for various flow rates occur in the Riser area to the surface.

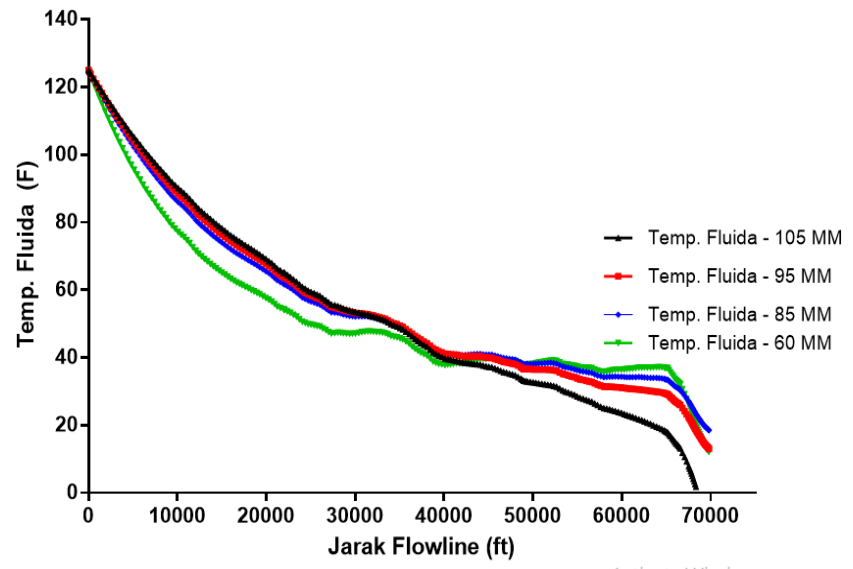

Fig. 6. Fluid temperature profile vs. flowline length

\subsection{MEG Injection for Hydrate Formation Prevention}

\subsubsection{MEG injection at 60 MMSCFD}

From the simulation results with varying doses of injection on the wet base composition of fluids, the same pressure and temperature and flowline dimensions at baseline conditions, with a flow rate of 60 MMSCFD production seen as shown in Figure 7. This figure shows the hydrate formation curve shifting to the left and increasingly to the left along with the increasing dose of MEG injection so that the working fluid operating conditions are on the right of the hydrate forming curve. The larger the injected MEG dose contributes causing the hydrate curve to move further to the left. At a MEG dose of $0.175 \mathrm{~mole} \%$, it still gives the difference of working fluid temperature with hydrate formation temperature of $12^{\circ} \mathrm{F}$ to be free from hydrate formation. 


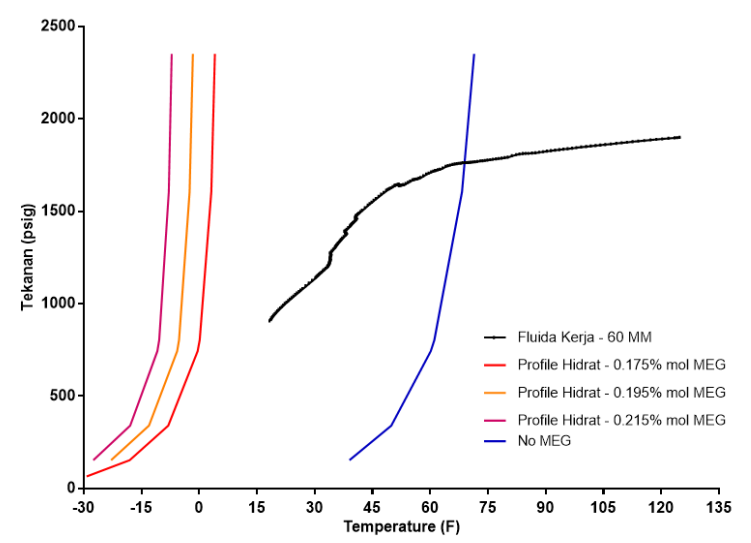

Fig. 7. Hydrate Formation Profiles at 60 MMSCFD

\subsubsection{MEG injection at 85 MMSCFD}

From the simulation results as shown below shows the hydrate forming curve shifting to the left and increasingly to the left as the MEG injection dose increases so that the working fluid operating conditions are to the right of the hydrate-forming curve. The larger the injected MEG dose contributes causing the hydrate curve to move further to the left. At an MEG dose of 0.175 mole $\%$, it still gives a working fluid temperature difference with hydrate forming temperature of $18^{\circ} \mathrm{F}$ to be free from hydrate formation.

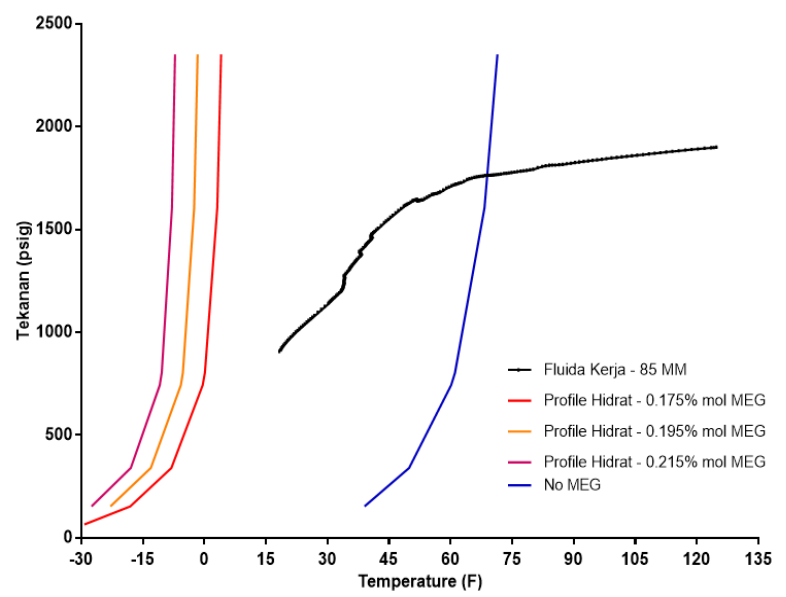

Fig. 8. Hydrate Formation Profiles at 85 MMSCFD.

\subsubsection{MEG injection at 95 MMSCFD}

From Fig. 9 it shows that the hydrate-forming curve also shifts to the left and increasingly to the left as the MEG injection dose increases. At a MEG dose of 0.175 mole\%, it still gives a working fluid temperature difference with a hydrate-forming temperature of $13^{\circ} \mathrm{F}$ and larger at larger MEG doses.

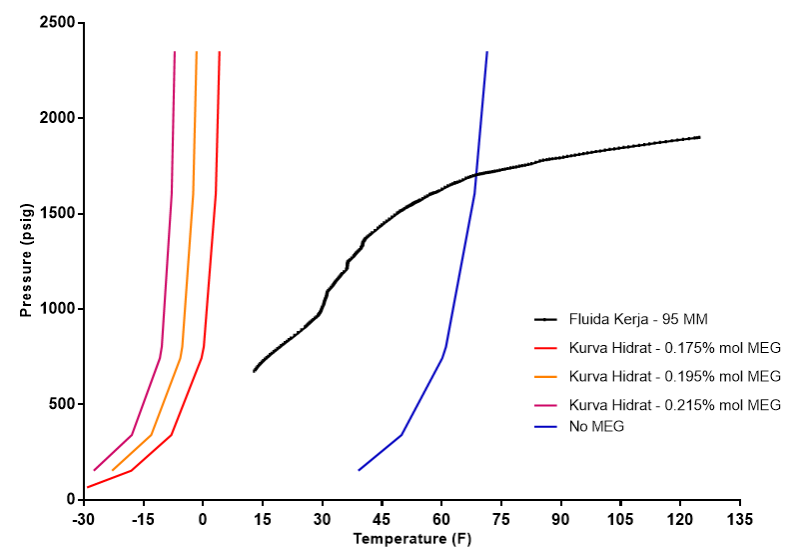

Fig. 9. Hydrate Formation Profiles at 95 MMSCFD

\subsubsection{MEG injection at 105 MMSCFD}

To simulate the 105 MMSCFD flow rate, the figure below shows the hydrate-forming curves also shifted to the left and increasingly to the left along with the larger dose of MEG injection as in the previous flow rate. At a MEG dose of 0.175 mole\%, it still gives a working fluid temperature difference with a hydrate forming temperature of $5.5^{\circ} \mathrm{F}$ and greater at larger MEG doses.

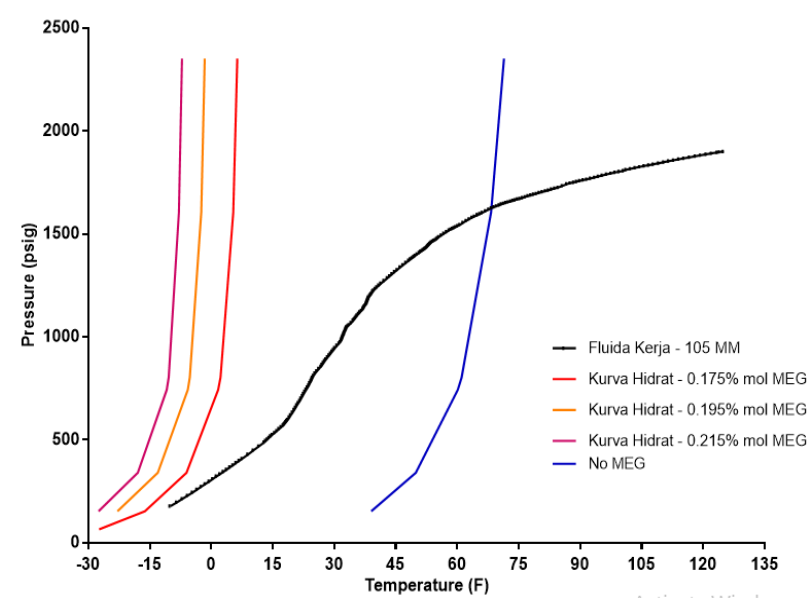

Fig. 10. Hydrate Formation Profiles at 105 MMSCFD

\subsection{Sensitivity analysis}

Hydrate formation temperature and pressure do not have a significant effect on the production flowrate, as shown in Table 5. The decrease in the flowrate of production has little impact on changes in pressure rise and temperature of hydrate formation, and this causes the hydrate to be more easily formed on the same fluid composition. Decrease in the flow rate of production will likely occur as the age of gas field production increases. 
Table 5. Sensitivity Analysis Results

\begin{tabular}{|c|l|c|c|}
\hline \multirow{3}{*}{ Flowrate } & MEG & $\begin{array}{c}\text { Hydrate } \\
\text { Formation } \\
\left.\text { Temperature( }{ }^{(} \mathbf{F}\right)\end{array}$ & $\begin{array}{c}\text { Pressure } \\
\text { (psig) }\end{array}$ \\
\hline \multirow{4}{*}{60} & No MEG & 69.14 & 1849 \\
\cline { 2 - 4 } & $0.175 \% \mathrm{~mol}$ & 3,42 & 1849 \\
\cline { 2 - 4 } & $0.195 \% \mathrm{~mol}$ & $-2,24$ & 1849 \\
\cline { 2 - 4 } & $0.215 \% \mathrm{~mol}$ & $-7,71$ & 1849 \\
\hline \multirow{5}{*}{85} & No MEG & 68,80 & 1762 \\
\cline { 2 - 4 } & $0.175 \% \mathrm{~mol}$ & 3,32 & 1762 \\
\cline { 2 - 4 } & $0.195 \% \mathrm{~mol}$ & $-2,33$ & 1762 \\
\cline { 2 - 4 } & $0.215 \% \mathrm{~mol}$ & $-7,79$ & 1762 \\
\hline \multirow{5}{*}{95} & No MEG & 68,29 & 1699 \\
\cline { 2 - 4 } & $0.175 \% \mathrm{~mol}$ & 3,27 & 1699 \\
\cline { 2 - 4 } & $0.195 \% \mathrm{~mol}$ & $-2,40$ & 1699 \\
\cline { 2 - 4 } & $0.215 \% \mathrm{~mol}$ & $-7,84$ & 1699 \\
\hline \multirow{4}{*}{105} & No MEG & 67,90 & 1621 \\
\cline { 2 - 4 } & $0.175 \% \mathrm{~mol}$ & 4,02 & 1621 \\
\cline { 2 - 4 } & $0.195 \% \mathrm{~mol}$ & $-2,48$ & 1621 \\
\cline { 2 - 4 } & $0.215 \% \mathrm{~mol}$ & $-7,91$ & 1621 \\
\hline
\end{tabular}

\subsection{Degree of subcooling}

Subcooling degrees are usually used as driving forces for hydrate formation, but do not include pressure effects. Comprehensively the driving factor for hydrate formation is a function of pressure, temperature, and concentration, but the calculations are not as simple as those done in subcooling. However, for multi-component systems (eg, natural gas), it can be seen from the simulation results that the higher flow rate with lower pressure gives a slightly smaller subcooling degree value change in the range of $65.72^{\circ} \mathrm{F}$ to $63.88^{\circ} \mathrm{F}$ for dose use MEG 0.175 mole\%. MEG dose increments increase the subcooling degree in the range of $63-65^{\circ} \mathrm{F}$ to $75-76^{\circ} \mathrm{F}$, as shown in Figure 11.

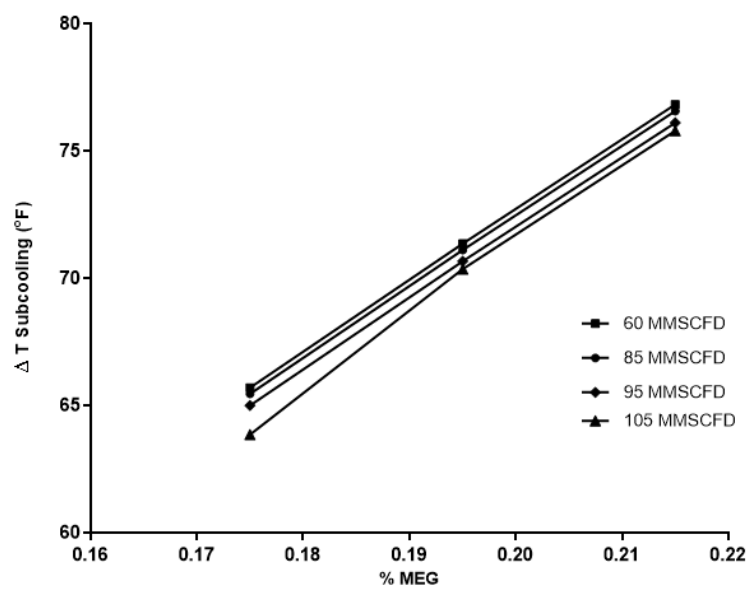

Fig. 11. Subcooling degree vs flow rate.

\section{Conclusions}

Based on the results of the research on the deep sea flowline modeling system using HYSYS v8.8 simulator on steady state based on actual data in the field, it can be drawn some key conclusions as a learning in understanding the characteristics of hydrate formation in deep sea gas field and influence of flow rate parameters with varying MEG levels to prevent hydrate formation. Under normal operating conditions a fluid flow is studied, without the use of an inhibitor, then a portion of the fluid flow of work is on the left side of the hydrate forming curve, hence hydrates will form in the range of operating conditions.

Based on the simulation results for the actual production flow rate, the hydrate is formed at a distance of about $17991 \mathrm{ft}(5.48 \mathrm{~km})$ from the wellhead that is in the first segment of the wellhead to the PLEM. For a higher production flow rate, hydrate formation occurs at a distance that is closer to the wellhead and also in the first segment. Hydrate formation does not have a major effect on the change in the decrease or increase in the flow rate of production. Decrease in the flow rate of production has little impact on changes in pressure rise and temperature of hydrate formation, and this causes the hydrate to be more easily formed on the same fluid composition.

At increasing MEG doses for each production flow rate, it can give a working fluid temperature difference with a hydrate formation temperature of $5.5^{\circ} \mathrm{F}$ to $64^{\circ} \mathrm{F}$, which means the hydrate-forming curve will shift to the left of the working fluid area so that the hydrate formation will be avoided. From the simulation results that the higher flow rate with lower pressure gives a slightly smaller subcooling degree value change in the range of $65.72^{\circ} \mathrm{F}$ to $63.88^{\circ} \mathrm{F}$ for the use of MEG doses of $0.175 \%$ mol. Increase in MEG dose increases subcooling degree in the range of about $63-65 \mathrm{oF}$ up to $75-76^{\circ} \mathrm{F}$. Addition of MEG dose of 0.175 mole $\%$ at each production flow rate gives different working fluid temperature with hydrate formation temperature of $5.5 \mathrm{oF}$ to $18 \mathrm{oF}$, so it is safe from the risk of hydrate formation.

Under baseline conditions with 85 MMSCFD flow rate, at 1900 psig pressure and an initial temperature of $125^{\circ} \mathrm{F}$, the addition of MEG dose of $0.175 \mathrm{~mol} \%$, lowered the hydrate-forming temperature from $67.8^{\circ} \mathrm{F}$ to $3.32^{\circ} \mathrm{F}$. as well as for increasing MEG doses, the greater the decrease in hydrate formation temperature.

\section{References}

[1] Camargo, R., Palermo, T., Sinquin, A. \& Glenat, (2000): Rheological characterization of hidrat suspension in oil dominated system. Gas Hidrats: Challenges for the Future, 912, 906-916

[2] Chaudari Piyush N. (2015): Development Of Hidrat Risk Quantification in Oil and Gas Production (Doctoral Desertation), Colorado School Of Mines, Golden Colorado

[3] Hammerschmidt E.G., (1934): Formation of Gas Hidrats in Natural Gas Transmission Lines. Ind. Eng. Chem, 26:851. 
[4] Carrol, John. (2014): Natural Gas Hidrats, Third Edition: A Guide for Engineers, Gulf Profesional Publishing Canada

[5] Davarnejad, R, Jam. Azizi, Jab. Azizi. (2014): Prediction of Gas Hydrate Formation using HYSYS Software International Journal of Engineering, 27, 1325-1330.

[6] Sloan E.D. (2000): Hidrat Engineering. Society of Petroleum Engineer (U.S.)

[7] Sloan Dendy. (1998): Offshore Hidrat Engineering Handbook, Centre for Hidrat research, Colorado School of Mines, Golden, Colorado

[8] Sloan, E.D. \& KOH, C.A. (2007): Clathrate Hidrats of Natural Gases.

[9] Turner D. et al., (2005): Development of a Hidrat Kinetic Model and It's Incorporation into the OLGA $2000^{\circledR}$ Transient Multiphase Flow Simulator. 5th International Conference on Gas Hidrats, 4018, Trondheim, Norway, p1231-1240.

[10] Vysniauskas, A \& Bishoi, P.R. (1985): Kinetics of Ethane Hidrat Formaton. Chemical Engineering Science, 40, 299-303.

[11] Vysniauskas, A \& Bishoi, P.R. (1985): Kinetics of Methane Hidrat Formaton. Chemical Engineering Science, 38, 1061-1072.

[12] Zerpa Luis E. (2013): A Practical Model to Predict Gas Hidrat Formation, Dissociation and Transportability in Oil and Gas Flowlines, Doctoral Desertation, Colorado School Of Mines, Golden, Colorado.

[13] Zhijian Liu. (2017): Study of Hidrat Deposition and Sloughing of Gas Dominated Pipelines Using Numerical and Analytical Models, Doctoral Desertation, Colorado School Of Mines, Golden, Colorado. 